\title{
The Rational Emotive Behavioral Therapy and Students' Defense Mechanisms
}

\author{
Farideh Hamidi, ${ }^{1, *}$ and Farshid Paidar ${ }^{1}$ \\ ${ }^{1}$ Department of Educational Sciences, Shahid Rajaee Teacher Training University, Tehran, IR Iran \\ "Corresponding author: Farideh Hamidi, Department of Educational Sciences, Shahid Rajaee Teacher Training University, Tehran, IR Iran. Tel: +98-2122970035, E-mail: \\ fhamidi@srttu.edu
}

Received 2015 November 18; Revised 2016 January 17; Accepted 2016 January 20.

\begin{abstract}
Background: Defense mechanisms are psychological operations which often prevent stressful norms, beliefs, and values to emerge and reach the level of consciousness.

Objectives: The aim of the present study was to investigate the effect of Rational Emotive Behavioral Therapy (REBT) on defense mechanisms of boy high school students at east Azerbaijan, Iran.

Patients and Methods: This experimental study was conducted on all male students $(n=680)$ enrolled in the second and third grades of high school in east Azerbaijan, Iran, during 2014 - 2015. To select the sample, first the defense style questionnaire (DSQ, Andrews et al. 1993) was completed by 150 students and among those who had the required conditions to participate in the study, 30 students were randomly selected and divided into the control $(n=15)$ and experimental $(n=15)$ groups. Eight sessions of the REBT were conducted on the experimental group. Data were analyzed using ANCOVA analysis with the SPSS software version 20.

Results: Results showed that after the interventions, a significant relationship was found between the control and experimental groups in terms of using mature and immature defense mechanisms $(\mathrm{P}<0.05)$. However, the relationship between the control and experimental groups was not significant in terms of the neurotic defense mechanism $(\mathrm{P}>0.05)$. In this regard, the rational emotive behavioral group counseling leads to reduction of using immature defense mechanisms $\left(\mathrm{F}_{(1,2)}=43.55, \mathrm{P}=0, \eta \mathrm{p}^{2}=0.67\right)$ and increase using of mature defense mechanisms $\left(\mathrm{F}_{(1,2)}=19.78, \mathrm{P}=0, \eta \mathrm{p}^{2}=0.42\right)$ among the students.

Conclusions: The results of the current study indicate that the REBT therapy can balance and improve defense mechanisms among male high school students.
\end{abstract}

Keywords: Rational Emotive Behavioral Therapy, Defense Mechanisms, Students

\section{Background}

The concept of anxiety is a basic concept in the literature of mental problems. Anxiety is defined as a feeling of fear caused by the feelings, memories, desires, and suppressed experiences that reach the level of consciousness. Anxiety can be considered as a state of tension that arouses people to do something. Anxiety is created by the conflict among Id, ego and superego in controlling the mental energy. The duty of anxiety is to alert the eminent danger. Mechanisms are not understandable without considering the anxiety that recalls them. Freud's second theory transferred the focus of exploration and therapy from instinctual impulseto the "I". I can realize anxiety and then move forces for defending the eminent peril caused by the accumulation of impulses. This theoretical revision by Freud puts more emphasis on the role of environment (noumenal and phenomenal environments). Hence, I would have two functions, to inhibit action and move- ment of emotions and impulses and to balance the environmental requirements (1). The history of employing defense in diagnosis of mental problems dates Freud's works (2), which were later corrected and published by his daughter Anna Freud in a series of seminal articles. Vaillant distinguished between defense styles in terms of their incidence at the stages of growth, i.e. rooted in different sexual mental phases and pointed out that mature defenses lead to healthier mental functioning (3). Andrews, Singh and Bond identified twenty defense mechanisms and divided them to three defense styles including mature, neurotic, and immature (4). Mature defense mechanisms are identified as efficient, normal, and adaptive exposure methods while, immature and neurotic defensive mechanisms are considered as inefficient and not adaptive. Immature defense is observed among adolescents and some mentally disordered patients. Neurotic defense is observed in hysteric and obsessive compulsive disorder (OCD) patients, as well as adults under stress. Mature defense is seen in 
healthy people (5). Defense mechanisms have three components: 1) an observable behavior (often a signal); 2) an impulse or intention which is not acceptable for the patient and functions as a stressor causing emotional conflict and 3) The process that links the observed behavior (or the signal) to the unacceptable intention or desire. The relation between intention and desire to the observable behavior or signal is only found through the interpretation of the therapist and the patient may reject or accept it (6). According to Freud, defensiveness is unavoidable even in the healthiest people. Also, in his view we have a defensive state all the times. The conscious demands and desires of Id must always remain hidden from the retribution eye of super-ego. Defensiveness cannot be eliminated even through specialized techniques such as psychoanalysis. At best, we can learn how to replace the defenses that distort the reality in large scales with those defenses that do this more delicately. Freud regards defense mechanisms very adaptive. In his view, these mechanisms are little justified lies that give the person the possibility to live by him/herself and the society. They enable individuals to cope with a mental threat without falling into the surrealistic thinking or psychosis. Mature defenses allow the biologic impulses to evolve in the constructive and useful ways (7). Many defense mechanisms basically emerge in a specific order and during different phases of childhood growth. When an individual steps adulthood, regardless of the age that defense styles has originated, she might employ several defenses altogether. In other words, an adult may use the defense mechanisms of loquacity, rational justification (emerged in the latent stage), identification with the mental image and/or the ideal object (emerged in the adolescence stage) and projective blame (emerged in the anal stage) (8). The attention to defense mechanisms has been on increase in the recent years (9). In the psychoanalysis system, every mental disorder is associated with certain nonadaptive defense mechanisms and they play an important role in the mental health of individuals $(10,11)$. Hence, the defense mechanisms logically have the capacity to be considered as one of the main therapeutic factors and receive high attention in the therapeutic interventions (12). Implicit and explicit findings emphasize the relationship between defense mechanisms and personality structure. In this regard, identification of defense mechanisms can open a way for recognition of individual differences and their personal structure. The attempt of defense mechanisms for removing forbidden thoughts or at least reducing them leads to stabilization of certain features and characteristics (1). Millon is among the scholars who had a revolutionary role in establishing the relationship between personality disorders and defense mechanisms. He believes that a persistent re- lationship exists among personality traits and the clinical spectrum of personality disorders with some defense mechanisms. He associate esschizoid personality disorder with intellectualization mechanism, avoidant personality with fantasy mechanism, dependent personality with introjection mechanism, histrionic personality with dissociation mechanism, narcissist personality with rationalization mechanism, antisocial disorder involved with acting out, obsessive-compulsive personality disorder with reaction formation, schizotypal personality disorder with undoing mechanism, and borderline personality disorder with repression (13). According to Maltby et al. (14) a number of positive personality traits such as the ability of forgiveness have a positive correlation with optimism, emotional intelligence, and self-respect and negative correlation with neurotic mechanisms. Hence, the presence of this personality trait can be effective in improvement of interpersonal relationship by employing mature mechanisms. In the recent studies, the relationship between defense mechanisms and different variables have been investigated including attachment styles (15), anger experience and expression (16), written emotional expression, psychological welfare (17), job exhaustion of airline personnel(18), psychological puberty (19), and psychological symptoms of self-damaging (20). The rational emotive behavioral therapy (REBT) assumes that human is born with either rational (direct) or irrational (twisted) thinking ability. People have the capacity of self-respect, enjoying thinking and speaking, loving, communicating with others, growing, and flourishing. They also have the capacity and preparation for self-destruction, avoiding thinking, procrastination, endless repetition of making mistakes, superstitions, intolerance, perfectionism, self-blame, and repressing the talents. The rational emotive behavioral therapy encourages people to accept who they are despite the mistakes they might have (21). Ellis emphasizes that blaming causes the majority of emotional agitations. If we want to remain mentally healthy, it is better to stop blaming ourselves and others and learn how to accept ourselves with all faults in an unconditional way. Ellis stipulates that we have a strong tendency to change our wishes and desires to musts, should, orders and demands. When we are upset, it is good to pay attention to despotic "musts", "shoulds", and "ought to". This kind of demands constitutes the basis of disordering emotions and unhealthy behaviors (22). Cognitive restructuring is the main method of cognitive therapy that teaches people how to improve them by replacing irrational beliefs with rational thoughts (23). In restructuring, the patients are educated to monitor their self-talk, identify self-incompatible talk, and replace it with talking to their negative self (24). Vulnerability of individuals to sadness changes with regard to the biological, phys- 
iological, and social factors. Human usually loves to enjoy their privacy, social relations, sexual relations, work, and recreation; however, their ineffective beliefs may not allow them. Ellis counts twelve irrational beliefs that upset individuals and prevents them from achieving their goals (25). Due to the importance of this approach for the beliefs system of people, many studies have investigated its efficiency for helping different groups of the society, such as investigating the effect of the REBT group therapy on reducing the anxiety among girl high school students (26), the effect of REBT on stress coping strategies and self-efficacy (27), the effect of combining REBT and art therapy on improvement of self-confidence and flexibility (28), and the effect of educational emotional model on the illogical beliefs and stress among the students (29). Regarding the importance of defense mechanisms in emergence of problems and the effectiveness of REBT, in this study we tried to answer the question that whether REBT has any effect on the defense mechanisms of boy students?

\section{Objectives}

The aim of the present study was to examine the effect of REBT on defense mechanisms of male high school students at east Azerbaijan.

\section{Patients and Methods}

The present study was an empirical study using pretest and posttest with a control group. In this study, the participants were selected by simple random sampling and assigned to two separate groups, control and experimental. Both groups received the posttest; then the independent variable was conducted on the experimental group and at the end, both groups were evaluated. The statistical population of study included all 2rd and 3rd grade male high school students of east Azerbaijan who enrolled in 2014 2015 academic year. The number of boys' high schools in the town was 4 , including 6802 rd and 3rd grade students in total. The size of sample in this study due to its experimental was 30 students (30). First, a clustered random selection was done, choosing one school among the 4 , then 150 questionnaires were distributed among 2rd and 3rd grade students of this school. Those who scored one standard deviation higher than the mean score in a defense style questionnaire included 45 students among which 30 were selected as the sample by the simple random sampling method and then the participants were randomly divided into experimental and control groups.

\subsection{Instruments}

Defense style questionnaire (DSQ-40) is constructed based on the defense hierarchy model. It was first developed in 1983 by Andrews et al. $(4,31)$ to investigate the defense mechanisms among normal and abnormal individuals. It consisted of 88 items that explored 24 mechanisms. This questionnaire was reviewed several times and its latest version was developed by Andrews et al. $(4,32)$ in 1993 , including 40 questions that explore 20 defensive mechanisms at three levels of mature, neurotic, and immature. The items of this questionnaire are responded based on a 9 degree scale from completely disagree to completely agree, and the respondent must choose her level of agreement with the statements on defense mechanisms (33). Besharat et al. (33). reported the Cronbach's alpha coefficient for mature, immature, and neurotic styles as $0.75,0.73$, and 0.74 , respectively and the retest validity coefficient with the interval of 4 weeks as 0.82 . Accordingly, DSQ-40 was proved to have a good validity in the studied population.

\subsection{Administration}

The content of counseling sessions is presented in the following. The first session started with introduction of members, warm-up, and the rules and objectives of the group were determined; and the subject of how to distinguish between suitable and unsuitable feelings was discussed with the adolescents. In the second session, to learn the main principles of the scientific method of thinking about ourselves, others, and life a group discussion and counseling with members were run. In the third session, the Ellis A-B-C model was taught. In the 4 th session, the focus was on how to distinguish between wishes and musts, identifying Ellis three basic musts and challenging them. In the 5th session, the focus was on the subject of how to solve our real problems along with our emotional problems, as well as changing the thoughts or actions against them. In the 6th session, the four pairs of beliefs were explored: 1) preferences vs. musts, 2) anti-awfulising vs. awfulising 3) high frustration tolerance vs. low frustration tolerance 4) acceptance of self or other or the world vs. self, other, or world damning. In the 7th session, the description of defensive mechanisms and styles, and their persistent effect on anxiety and irrational beliefs were presented in terms of REBT of Ellis. In 8th session, the ability of promoting the tolerance capacity was discussed with members and a final review on the contents and materials provided so far was done.

\subsection{Data Analysis Method}

To examine research dependent variables, descriptive statistics such as mean and standard deviation was used. 
Also, for testing the research hypotheses inferential statistics including covariance analysis and the Levin's variance homogeneity test was run. The level of significance was considered 0.05 .

\section{Results}

In this part, mean and standard deviation of defensive mechanisms in the pretest and posttest are presented (Table 1).

Table 1. Descriptive Indexes of Subcategories of Defensive Mechanisms ${ }^{\mathrm{a}}$

\begin{tabular}{|ccc}
\hline Variable & Control & Experimental \\
\hline Mature & & \\
Pre-test & $44.27 \pm 9.84$ & $49.07 \pm 9.23$ \\
\hline Post-test & $44.47 \pm 9.54$ & $57.07 \pm 5.13$ \\
\hline Immature & & \\
\hline Pre-test & $148.60 \pm 8.31$ & $153.07 \pm 15.38$ \\
\hline Post-test & $148.13 \pm 8.45$ & $116.13 \pm 18.51$ \\
\hline Neurotic & & \\
\hline Pre-test & $47.00 \pm 11.40$ & $47.67 \pm 9.75$ \\
\hline Post-test & $47.13 \pm 11.23$ & $45.47 \pm 7.64$ \\
\hline
\end{tabular}

${ }^{\mathrm{a}}$ Values are expressed as mean $\pm \mathrm{SD}$.

As shown in Table 1, there is a difference in the scale of defense mechanism in the mean scores of pretest and posttest of the two groups. It is also observed that in the experimental group, the mean scores are reduced in the posttests of neurotic and immature variables while increased in the mature variable. For testing the variance equality, data were examined with the Levin's homogeneity test. Results showed that the variance of control and experimental groups are homogenous in the subscales of mature $(F=0.776, P=0.082)$, immature $(F=1.810, P=0.189)$ and neurotic $(\mathrm{F}=1.959, \mathrm{P}=0.173)$. Also, the multivariate covariance analysis tests including Pillai'strace, Wilk's Lambda, hoteling trace, etc. were done. Also, the value of Wilk's Lambda was estimated (0.350) and F (1.856) with degrees of freedom 3 and 26 which showed significant homogeneity and indicated that the control and experimental groups had a significant difference in terms of at least two dependent variables. As a result, covariance analysis was used for data analysis. The result of covariance analysis on the general adaptability variable and its subcategories in control and experimental groups are presented in Table 2.

To investigate the mean scores of defensive mechanisms in the control and experimental groups (with pretest control), ANCOVA analysis was used. As shown in
Table 2, the calculated $\mathrm{F}$ in the mean score of mature and immature categories between the control and experimental groups (with pretest control) was significant at the error level of 5 percent. Hence, the null hypothesis was rejected and at the confidence level of 95\%, a significant difference was found in mean scores of mature and immature mechanisms of the control and experimental groups. Also, the group rational emotive behavioral counseling was effective in reducing the use of immature defense mechanisms $\left(\mathrm{F}_{(1,2)}=43.55, \mathrm{P}=0, \eta \mathrm{p}^{2}=0.67\right)$ and increasing the use of mature defenses $\left(\mathrm{F}_{(1,2)}=19.78, \mathrm{P}=0, \eta \mathrm{p}^{2}=0.42\right)$ among high school students. However, the calculated $\mathrm{F}$ in the neurotic mean scores of the experimental and control groups (with pretest control) was not significant at the error level of $5 \%$ hence the null hypothesis was accepted. Thus, results showed that REBT had no effect on reducing the use of neurotic defenses among high school students $\left(\mathrm{F}_{(1,2)}=0.46, \mathrm{P}=\right.$ $\left.0.499, \eta \mathrm{p}^{2}=0.017\right)$.

\section{Discussion}

According to the results of the current study, the REBT can lead to reducing the use of immature defense mechanisms and also increasing the use of mature ones among the participants of the experimental group compared to those at the control group in the pretest. In a study by Javaheri et al. (16) the relationship between defense mechanisms and the experience and expression of anger was investigated among 213 girl students educating at undergraduate courses of Shahid Beheshti university. The results showed that mature defenses have a positive correlation with the experience and control of anger, while showing a negative correlation with anger expression and its subscales such as verbal and physical emergence of anger, angry mood and reactions. Also, immature and neurotic mechanisms had a negative correlation with the experience and control of anger, and a positive correlation with anger expression and its subscales. In fact, those who use mature defenses can experience feelings such as anger and thus are able to control their anger more effectively. However, those who use immature and neurotic defense mechanisms avoid experiencing their feelings which does not mean eliminating it, but the feeling is being suppressed and projects through behaviors which are sometimes out of control. As a result, people should be educated to use mature defense mechanisms. Moreover, defense mechanisms have been investigated in relation to different behaviors such as depression, anxiety, normal people, educational advance, etc. by different researchers during recent years $(6,17,19,20,34,35)$. In relation to the research variables, the results of covariance analysis of experimental and control groups determined that all variables ex- 
Table 2. Test of Traces to Find the Difference Between Scores of Defense Mechanisms in the Control and Experimental Groups

\begin{tabular}{lccccc}
\hline Source of Changes & SS & df & MS & Fta2 & P \\
\hline Mature & 727.008 & 1 & 727.008 & 19.778 & 0 \\
Immature & 8265.957 & 1 & 8265.957 & 43.551 & 0 \\
Neurotic & 26.019 & 1 & 26.019 & 0.423 & 0.469 \\
\hline
\end{tabular}

cept the neurotic defense mechanism are statistically significant. According to McAdams (36), the neurotic defense mechanisms are incompatible ways to encounter the anxiety due to the hidden and suppressed desires; it can be said that it is more profound and complicated compared to other variables and requires more attention and investigation. Hence, the short term of this therapy can be one of the reasons that caused it to be insignificant. In the view of Blackman (8) humans use these defenses to remove their undesired feelings and thoughts from the conscious realm; and use a range of harmless jokes to attacking their beloved ones to avoid the painful memories of the past; these defenses help us to cover their sadness or transfer it to others. In explaining the findings of this study, it can be said that since both variables of these hypothesis i.e. the REBT and defense mechanisms involve the beliefs and opinion of people, the existence of a relationship between the two variables is logical theoretically and REBT can be helpful in determining the amount of using defense mechanisms. When faced with anxiety caused by various educational situations, adolescents resort to a series of defense mechanisms that can be balanced in a number of ways, including therapies, how to avoid becoming upset, and increasing the tolerance to failures and challenging the irrational thoughts and beliefs and musts that are inducted to us by the environment or built by our minds, in total finding a philosophy of life. This study was done on the boy students and regarding gender differences, it is not generalizable to girl students. Due to the lack of access to the list of all members of the population, cluster sampling method was used. It is suggested that REBT is taught to the educational counselors and mentors with an applied purpose so that by implementing this training the irrational thoughts of high school students which are the cause of their anxiety, and the subsequent immature and neurotic defense mechanisms are treated and cured.

\section{Acknowledgments}

We greatly appreciate all students and directors of schools who cooperated with us in this research.

\section{References}

1. Ghorbani N. Intensive Short-Term Dynamic Psychotherapy. Basics and Techniques Tehran: Samt; 1382.

2. Freud S. The neuro-psychoses of defence. standard ed. 3. ; 1894. pp. 4561.

3. Vaillant GE. Ego mechanisms of defense: a guide for clinicans and researchers. American Psychiatric Pub; 1992.

4. Andrews G, Singh M, Bond M. The Defense Style Questionnaire. J Nerv Ment Dis. 1993;181(4):246-56. [PubMed: 8473876].

5. Sadok BJ, Sadok VA. The summary of psychiatry. Tehran.; 2008.

6. Hashemi MS. The relationship between educational ignorance and defensive mechanisms with progress motivation in students of IsfahanUniversity of Medical Sciences. Tehran, Iran: Allameh Tabatabaiee University; 2012.

7. shahiBarati H. In: Psychological health. Ravan, editor. ; 2004.

8. Blackman JS. 101 defenses: How the mind shields itself. Psychology Press; 2004.

9. Cramer P. Defensmecanisms in psychology today I am Psychology. If Res Person. 2005(5):637-46.

10. Bond M, Perry JC. Long-term changes in defense styles with psychodynamic psychotherapy for depressive, anxiety, and personality disorders. Am J Psychiatry. 2004;161(9):1665-71. doi: 10.1176/appi.ajp.161.9.1665. [PubMed: 15337658].

11. Blaya C, Kipper L, Heldt E, Isolan L, Ceitlin LH, Bond M, et al. [BrazilianPortuguese version of the Defense Style Questionnaire (DSQ-40) for defense mechanisms measure: a preliminary study]. Rev Bras Psiquiatr. 2004;26(4):255-8. doi: 10.1590/S1516-44462004000400010. [PubMed: 15729460].

12. Tahery N, Hojjati H, Kamangar S, Mousavi SZ, Ghorbani S, Farhadi S, et al. Comparative defense style used by nurses in stressful situations. $J$ Health Prom Manag. 2013;2(4):57-64.

13. Millon T, Davis R. Personality disorders in modern life. New York: Wiley; 2000.

14. Maltby J, Day L, Barber L. Forgiveness and mental health variables: Interpreting the relationship using an adaptational-continuum model of personality and coping. Pers Individ Dif. 2004;37(8):1629-41.

15. Abolghasemi A, Mahmoodi $\mathrm{H}$, Soleimani E. Investigating the role of attachment styles and defense mechanisms in distinguishing smoking and non-smoking students. J Med Uni Sabzvar. 2009;16(3):134-41.

16. Javaheri A, Ghanbari S, Zarandi AR. Relationship between defense mechanisms with experience and express of angerin female university students. J Appl Psychol. 2011;5(18):97-100.

17. Ahadi B. , Sotudeh M. , Habibi Y. . Comparing psychological welfare and defense mechanisms in students with stuttering tongue and normal students. School Psychology Journal. 2012;4(1):6-22.

18. Sepidedam FS, Karimi Y. Investigating the use of defense styles in evaluation of job exhaustion of airline staff of I.R.I. Quarterly of Organizational and Occupational Counseling. 2012;13(4):69-82.

19. Cramer P. Psychological maturity and change in adult defense mechanisms. J Res Person. 2012;46(3):306-16.

20. Sarno I, Madeddu F, Gratz KL. Self-injury, psychiatric symptoms, and defense mechanisms: findings in an Italian nonclinical sample. Eur Psychiatry. 2010;25(3):136-45. doi: 10.1016/j.eurpsy.2009.05.007. [PubMed: 19695845]. 
21. ary J. Theory and application of counseling and psychotherapy. Tehran: Arasbaran; 2013.

22. Ellis A. Rational emotive behavior therapy: It works for me-it can work for you. Prometheus Books; 2004.

23. Williams SK, Ellis LA, Williams G. A 3D digital medical photography system in paediatric medicine.JVis Commun Med. 2008;31(3):91-8. doi: 10.1080/17453050802382839. [PubMed: 19085609].

24. Spiegler MD. Behavior therapy ll: Cognitive - behavioral therapy Boston: Lahaska Press; 2005. pp. 320-59.

25. firoozbakht M. Albert Ellis: fifty years of REBT. Tehran: Danjeh; 2003.

26. Yousefabad MZ, Borhani LG, Piri I. Group Council Effect Regarding to its Cognitive-behavioural-emotional Factors in Decreasing Girl High School Students Anxiety. Procedia Soc Behav Sci. 2013;84:1059-62.

27. Kim MA, Kim J, Kim EJ. Effects of rational emotive behavior therapy for senior nursing students on coping strategies and self-efficacy. Nurse Educ Today. 2015;35(3):456-60.

28. Roghanchi M, Mohamad AR, Mey S, Momeni KM, Golmohamadian M The effect of integrating rational emotive behavior therapy and art therapy on self-esteem and resilience. Arts Psychother. 2013;40(2):17984 .

29. Matin A, Looyeh MY, Afrooz GA, Dezhkam M. The effect of group ratio- nal emotive behavior restructuring on mental health of parents of exceptional children. Procedia Soc Behav Sci. 2012;46:1872-5.

30. Delavar A. Principles of theoretical and practical research in the humanities and social sciences. 3th ed. Tehran: Roshd; 2013.

31. Hayashi M, Miyake Y, Minakawa K. Reliability and validity of the Japanese edition of the Defense Style Questionnaire 40. Psychiatry Clin Neurosci. 2004;58(2):152-6.

32. Sinha BK, Watson DC. Personality disorder clusters and the Defence Style Questionnaire. Psychol Psychother. 2004;77(Pt1):55-66. doi: 10.1348/147608304322874254. [PubMed: 15025904].

33. Besharat $M$, Sharifi $M$, Irvani $M$. The relationship between attachment styles and defense mechanisms. J Psychol. 2011;3(5):277-89.

34. Rahmatian F. The relationship between perception of parenting on the subjective relations and defensive mechanisms. Allameh Tabatabaiee University; 2013. Master's thesis.

35. Parekh MA, Majeed H, Khan TR, Khan AB, Khalid S, Khwaja NM, et al Ego defense mechanisms in Pakistani medical students: a cross sectional analysis. BMC psychiatry. 2010;10(1):1.

36. McAdams DP. The role of defense in the life story. $J$ Person. 1998;66(6):1125-46. 